\title{
Staphylococcal enterotoxin B increases the severity of type II collagen induced arthritis in mice
}

\author{
Paul H Wooley and Barbara Cingel
}

\begin{abstract}
Objective-To observe the influence of $T$ cell subset changes on the development of experimental arthritis, by using the bacterial superantigen staphylococcal enterotoxin B (SEB) to modulate the $T$ cell repertoire during the arthritogenic response to type II collagen (CII) in vivo.

Methods-DBA/1 mice were injected with SEB before immunisation with CII, and assessed for the development of collagen induced arthritis (CIA) and an immune response to CII. Mice with established arthritis were also treated therapeutically with SEB. Flow cytometry was used to evaluate the effect of the therapy on $T$ cell subsets and $T$ cell receptor (TCR) V $\beta$ expression.
\end{abstract}

Results-Mice injected with SEB developed arthritis significantly faster than saline treated control animals, and developed more severe clinical features. Mice treated with SEB after the onset of CIA were also observed to progress more rapidly to a severe arthritis than mice treated with saline alone. The level of antiCII antibody was not affected by SEB injection. Flow cytometric analysis of TCR expression in mice 21 days after injection of CII showed decreased expression of $\mathrm{V} \beta 6$ and $\mathrm{V} \beta 8$ cells in SEB treated mice, compared with collagen immunised control mice. Injection of SEB alone caused a decrease in VB8, but not VB6 $T$ cells compared with the values in normal DBA/1 mice. No significant variations in the $T$ cell repertoire were detected 70 days after CII immunisation. Conclusions-Treatment with the bacterial enterotoxin SEB before the induction of arthritis did not suppress the immunological or arthritogenic response to CII in DBA/1 mice, despite the modulation of the VB8 $T$ cell subset. Treatment of mice with established arthritis using SEB provoked a more severe disease course.

(Ann Rheum Dis 1995; 54: 298-304)

Collagen induced arthritis (CIA) in mice is an experimental disease model which resembles rheumatoid arthritis (RA) with respect to both the histopathological features of arthritis and immunogenetic regulation by the major histocompatibility complex (MHC). A close parallel is observed between the class II MHC (HLA-DR) association in RA and the strict MHC association seen in CIA. ${ }^{2}$ The immunogenetic analysis of susceptibility to CIA in mice indicates that both the MHC ( $\mathrm{H}-2)$ phenotype and the $\mathrm{T}$ cell repertoire may be critical in the development of autoimmunity. Recent evidence has suggested a potential role for the minor lymphocyte stimulating (Mls) genes in CIA susceptibility. ${ }^{34}$ The Mls locus acts in the selection of the $T$ cell repertoire, as $\mathrm{T}$ cells that recognise Mls antigens in context with self MHC are clonally deleted in the thymus, ${ }^{56}$ and it has been suggested that a dysfunction in the Mls system may result in the preservation of self reactive $\mathrm{T}$ cells. ${ }^{3} \mathrm{CIA}$ is associated with $\mathrm{H}-2^{\mathrm{q}}$, which is characterised by the absence of I-E. Thus $\mathrm{H}-2^{\mathrm{q}}$ mice express V $\beta 8$ and V $\beta 6$ T cells, with the exception of the CIA resistant SWR strain (because of a gene deletion). ${ }^{7}$ The role of the V $\beta 8$ subset in the development of CIA remains controversial, as SWR mice are also complement deficient. ${ }^{8}$ Although a recent report suggested that the depletion of $\mathrm{V} \beta 8$ cells was effective in preventing the onset of CIA, ${ }^{9}$ this finding was not confirmed in a similar study. ${ }^{4}$ Despite these variable findings, a limited number of $\mathrm{V} \beta$ genes in the 'autoimmune' $T$ cell receptor (TCR) repertoire may be responsible for the arthritogenic response to collagen.

The action of the Mls antigen system in $\mathrm{T}$ cell selection is mimicked by the activities of staphylococcal enterotoxins. In vivo administration of staphylococcal enterotoxin B (SEB) to neonatal mice causes a complete deletion of mature $\mathrm{V} \beta 8$ and $\mathrm{V} \beta 3 \mathrm{~T}$ cells by day 10 , in contrast with the preservation of cells expressing $\mathrm{V} \beta 6 .{ }^{10}$ This clonal deletion presumably arises as a result of neonatal tolerance of SEB. In contrast, enterotoxins are strongly mitogenic in vitro, and expand particular V $\beta \mathrm{T}$ cell subsets. The mitogenic profile of SEB indicates that $\mathrm{V} \beta 3, \mathrm{~V} \beta 7, \mathrm{~V} \beta 8$, and V $\beta 17 \mathrm{~T}$ cells are clonally expanded, ${ }^{11}{ }^{12}$ and while in vivo administration of SEB does not alter the absolute number of lymph node $T$ cells, increased V $\beta 8$ expression occurs in a dose dependent manner. ${ }^{13}$ However, it has been suggested that SEB induced V $\beta 8$ cells may enter a state of profound anergy, ${ }^{14}$ characterised by failure to proliferate in response to anti-V $\beta 8$, SEB, or IL-2 in vitro. This anergy may be confined to the $\mathrm{CD} 4 \mathrm{~T}$ cell subset, ${ }^{15}$ leaving activity intact in V $\beta 8$ CD8 T suppressor/cytotoxic cells. An influence on the CD4 T cells is supported by findings that SEB 
in vivo is immunosuppressive to antibody generation $^{16}$ and the delayed type hypersensitivity response. ${ }^{17}$ The present study used CIA as an experimental model to examine the hypothesis that superantigenic modification of the $T$ cell repertoire may alter the activity of self reactive cells and change susceptibility to autoimmune disease.

\section{Methods}

ANIMALS

Female DBA/1 (H-2q) LacJ mice (seven to eight weeks old) were obtained from Jackson Labs (Bar Harbor, Maine), and housed in the Department of Laboratory Animal Resources at Wayne State University, in accordance with $\mathrm{NIH}$ animal care guidelines. Mice were housed randomly, and identified by ear tags. All procedures commenced following a two week period of quarantine.

\section{INDUCTION AND ASSESSMENT OF COLLAGEN} INDUCED ARTHRITIS

Bovine type II collagen was solubilised at $2 \mathrm{mg} /$ $\mathrm{ml}$ in $0.01 \mathrm{~mol} / 1$ acetic acid overnight at $4^{\circ} \mathrm{C}$, and emulsified with an equal volume of cold Freund's complete adjuvant (FCA) containing $2 \mathrm{mg} / \mathrm{ml}$ Mycobacterium tuberculosis H37Ra (Difco, Detroit). Mice were injected intradermally at a single site at the base of the tail with $100 \mu \mathrm{l}$ of cold emulsion as described elsewhere. ${ }^{18}$ Mice were monitored by daily examination for the onset of disease, which was usually characterised by erythema and oedema in a single paw. After the onset of arthritis, the joints were measured with a constant tension caliper (Schnelltaster System, Kroplin, FRG) to follow the progression of joint swelling during the course of the disease. Each limb was assigned a joint index according to the following score: $0=$ normal; $1=$ joint swelling and erythema; 2 = visible joint distortion; $3=$ ankylosis. Animals affected with arthritis were clinically assessed five times per week until 10 weeks after immunisation, and paw measurements were made three times per week. Mice without signs of arthritis 10 weeks after immunisation were considered disease negative.

\section{TREATMENT WITH STAPHYLOCOCCAL} ENTEROTOXIN B

SEB (Toxin Technology, Sarasota, FL) was dissolved in sterile saline solution to a concentration of $400 \mu \mathrm{g} / \mathrm{ml}$. The table summarises the groups of mice and their treatments. Ten

\begin{tabular}{llllr}
\multicolumn{2}{l}{ Experimental treatment protocol } \\
\cline { 2 - 4 } Group & Immunisation & Treatment & Assessment & $n$ \\
\hline 1 & Type II collagen + FCA & $40 \mu \mathrm{g}$ SEB & Clinical & 10 \\
2 & Type II collagen + FCA & Saline & Clinical & 10 \\
3 & FCA & $40 \mu \mathrm{g}$ SEB & Clinical & 6 \\
4 & Type II collagen + FCA & $40 \mu \mathrm{g}$ SEB & Flow cytometry (day 21) & 4 \\
5 & Type II collagen + FCA & Saline & Flow cytometry (day 21) & 4 \\
6 & FCA & $40 \mu \mathrm{g}$ SEB & Flow cytometry (day 21) & 4 \\
7 & Saline & Saline & Flow cytometry (day 21) & 4 \\
8 & Type II collagen + FCA & $40 \mu \mathrm{g}$ SEB & Clinical (after onset) & 12 \\
9 & Type II collagen + FCA & Saline & Clinical (after onset) & 12 \\
\hline
\end{tabular}

FCA = Freund's complete adjuvant; SEB = staphylococcal enterotoxin B.
DBA/1 mice (group 1) were prophylactically injected intraperitoneally with $100 \mu \mathrm{l}(40 \mu \mathrm{g})$ of SEB one day before immunisation with collagen (this dose has been reported as effective in modulating $\mathrm{V} \beta \mathrm{T}$ cell populations in vivo $\left.{ }^{13}\right)$. Ten control mice received $100 \mu$ l of sterile saline (vehicle control) and immunisation with collagen (group 2), while six control mice received $100 \mu \mathrm{l}(40 \mu \mathrm{g})$ of SEB and immunisation with FCA alone (group 3). Separate groups of four DBA/1 mice (groups 4-6) were immunised and treated by these same three procedures but underwent flow cytometric analysis at day 21. Control normal (unimmunised untreated), DBA/1 mice which received sterile saline alone were included in the assessment (group 7). To examine the influence of SEB on established arthritis, DBA/1 mice were immunised with $\mathrm{CII}$ and at the first signs of visible joint disease, the animals were injected with either $100 \mu \mathrm{l}(40 \mu \mathrm{g})$ of SEB (group 8) or sterile saline (group 9).

FLOW CYTOMETRIC ANALYSIS

Four mice were sacrificed at day 21 or day 70 after immunisation, lymph nodes (inguinal and popliteal) removed, and single cell suspensions made for flow cytometric analysis using techniques described previously. ${ }^{19}$ Spleen cells were not examined, because the spleen population does not appear to participate in the development of CIA. ${ }^{20}$ Cells $\left(10^{6}\right)$ were resuspended in $100 \mu \mathrm{l}$ phosphate buffered saline (PBS) containing $2 \%$ fetal calf serum (FCS), $20 \mathrm{mmol} / \mathrm{l}$ sodium azide and an appropriate dilution of the primary antibody to CD5 (Lyt1; rat IgG2a from ATCC clone 53-7.313, prepared as described previously ${ }^{19}$ ), CD4 (L3T4; rat IgG1 from ATTC clone GK1.5, prepared as described previously ${ }^{19}$ ), CD8 (Lyt2.1; IgG3 mouse monoclonal antibody 49-31.1, Cedarlane, Ontario), or 100 $\mu l$ of PBS/FCS alone. After incubation on ice for 20 minutes, the cells were washed by the addition of $2 \mathrm{ml}$ of cold PBS, centrifuged at $1500 \mathrm{~g}$ for 10 minutes, and resuspended in 100 $\mu l$ PBS/FCS containing either $1 / 100$ dilution of fluorescein isothiocyanate (FITC) conjugated goat anti-mouse Ig (Tago), or $1 / 10$ dilution of goat anti-rat Ig F(ab') (Jackson). Cell suspensions were analysed using a fluorescence activated cell sorter. Dead cells, erythrocytes, and granulocytes were excluded from the analysis by the construction of appropriate gates based on forward and $90^{\circ}$ scatter. Re-analysis of the mononuclear cell population for fluorescence intensity determined the percentage of positive cells for each cell marker. Appropriate corrections for background staining and autofluorescence were included in the analysis.

Two colour flow cytometry was used to determine TCR expression. Cells $\left(10^{6}\right)$ were resuspended in an appropriate dilution of FITC conjugated antibody to $\mathrm{CD} 3$ (Clone 500A2, hamster IgG; Pharmingen, CA). One of the following phycoerythrin conjugated anti$V \beta$ sera library (Pharmingen, CA) were added: $\mathrm{V} \beta 2$ (Clone B20.6, rat IgG2a), V $\beta 3$ (Clone 
$\mathrm{KJ}-25$, hamster IgG), V $\beta 5.1,5.2$ (Clone MR94, mouse IgG1), V $\beta 6$ (Clone $R R 4-7$, rat IgG2b), V $\beta 7$ (Clone TR310, rat IgG2b), Vß8.1, 8.2 (Clone MR5-2, mouse IgG2a), V $\beta 9$ (Clone MR10-2, mouse IgG1), V $\beta 11$ (Clone RR3-15, rat IgG2b), or V $\beta 14$ (Clone 14-2, rat $\operatorname{IgM})$. After incubation and washing, cells were resuspended in PBS and analysed by flow cytometry. Two dimensional analysis of the mononuclear cell population for red and green fluorescence determined the percentage of cells dual positive for the pan T cell CD3 marker and the library of $\mathrm{V} \beta$ markers.

ANTIBODY RESPONSES TO TYPE II COLLAGEN

The antibody responses to CII were assessed using an enzyme linked immunosorbent assay (ELISA) assay described previously. ${ }^{21}$ ELISA plates were coated overnight at $4^{\circ} \mathrm{C}$ with 3 $\mu \mathrm{g} /$ well of CII. Plates were washed three times with PBS/Tween, and blocked by the addition of $5 \%$ bovine serum albumin (BSA)/PBS. Serum samples diluted $1 / 200$ in PBS/BSA were dispensed in triplicate. A standard serum was titred on each plate, and negative controls were included in the assay. The plates were incubated overnight at room temperature, and washed three times with PBS/Tween. Goat anti-Ig conjugated with alkaline phosphatase was added, and incubation continued for one hour at $37^{\circ} \mathrm{C}$. After the plates were washed, $100 \mu \mathrm{l}$ of paranitrophenyl phosphate solution in diethanolamine buffer was added to each well, and the reaction allowed to proceed for 20 minutes in the dark. The plates were read at $405 \mathrm{~nm}$ using a Photospectrometer (Molecular Devices), and the data analysed using the SOFTmax analytical software package. Antibody levels were expressed as units derived from the standard curve.

CELL PROLIFERATIVE RESPONSES

Lymph nodes were removed at sacrifice from six mice in groups $1-3$, and mitogen responses to concanavalin A (con A) (Sigma, St Louis, MO), lipopolysaccharide (LPS) (Difco, Detroit, $\mathrm{MI}$ ) and SEB, and antigen responses to collagen were determined as described previously. ${ }^{22}$ Single cell suspensions were made in RPMI-1640 (Gibco, Grand Island, NY) supplemented with $10 \%$ FCS. Proliferative responses to con A, LPS or SEB were measured by culturing $2.5 \times 10^{5}$ cells with $2.5 \mu \mathrm{g} / \mathrm{ml}$ of con A, $10 \mu \mathrm{g} / \mathrm{ml}$ of LPS, $2.5 \mu \mathrm{g} / \mathrm{ml}$ of SEB, or $25 \mu \mathrm{g} / \mathrm{ml}$ of collagen in RPMI-1640 supplemented with $10 \% \mathrm{FCS}$ and $40 \mu \mathrm{mol} / 12$ 2-mercaptoethanol in 96 well tissue culture plates (Costar). After three days incubation at $37^{\circ} \mathrm{C}$, wells were pulsed with $20 \mu \mathrm{l} /$ well $3-(4,5-\mathrm{di}-$ methylthiazoyl-2)-2,5-diphenyltetrazolium bromide (MTT) at $10 \mathrm{mg} / \mathrm{ml}$ in sterile PBS. Plates were incubated for 24 hours at $37^{\circ} \mathrm{C}$, and 180 $\mu l$ of supernatant removed from each well and replaced with $180 \mu \mathrm{l}$ of $10 \%$ sodium dodecyl sulphate in PBS. After incubation at $37^{\circ} \mathrm{C}$ for four hours, the optical density of the wells at $590 \mathrm{~nm}$ was determined using the microplate spectrophotometer. Proliferation results were expressed as $\mathrm{OD}_{590}$ units, corrected for the background proliferative response observed in cultures containing medium alone.

STATISTICAL ANALYSIS

Data were analysed using the SPSS-PC (SPSS Inc., Chicago, IL) statistical software package. The group comparisons were performed using $\chi^{2}$ test or the Mann-Whitney test for independent samples of non-parametric data.

\section{Results}

INFLUENCE OF SEB PRETREATMENT ON COLLAGEN INDUCED ARTHRITIS

Figure 1 shows the effect of SEB injection upon the development of CIA. DBA/1 mice injected with SEB and immunised with collagen developed arthritis significantly faster (mean day of onset $37 \cdot 4$ ) than control animals injected with saline and immunised with collagen (mean day of onset 56.7$)(p<0.01$ ), although the final disease incidence was similar $(80 \%)$. Mice injected with SEB and immunised with FCA alone did not develop arthritis. Figure 2 shows the effect of SEB on the severity of the arthritis. Mice injected with SEB and immunised with collagen developed a similar number of involved paws, but significantly more severe clinical disease (assessed by the maximum disease index) than control animals $(\mathrm{p}<0.02)$.

The arthritis in DBA/ 1 mice treated with a single injection of SEB $40 \mu \mathrm{g}$ at the onset of disease (fig 3) progressed faster than in control mice treated with saline, with significant differences in the arthritis score occurring from one week after onset and sustained throughout the assessment period $(\mathrm{p}<0.05)$ at week 1 , $\mathrm{p}<0.02$ at week 5).

FLOW CYTOMETRIC ANALYSIS

Figure 4 shows the results of the flow cytometric analysis of lymph node cells from

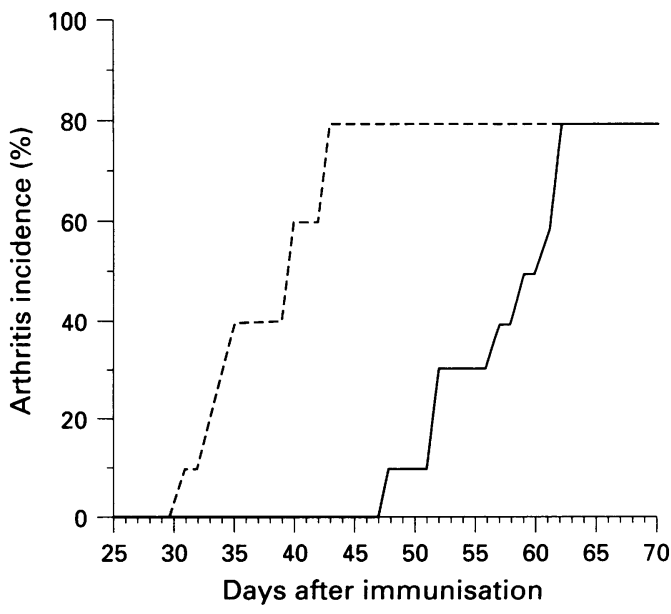

Figure 1 Effect of staphylococcal enterotoxin B (SEB) on the incidence of type II collagen induced arthritis. Groups of $10 \mathrm{DBA} / 1$ mice were injected intraperitoneally with $40 \mu \mathrm{g}$ $S E B$ in sterile saline (---), or sterile saline alone (control) $(-)$ at day -1 . All mice were immunised with $100 \mu \mathrm{g}$ of bovine type II collagen on day 0 , and assessed for the development of arthritis. 


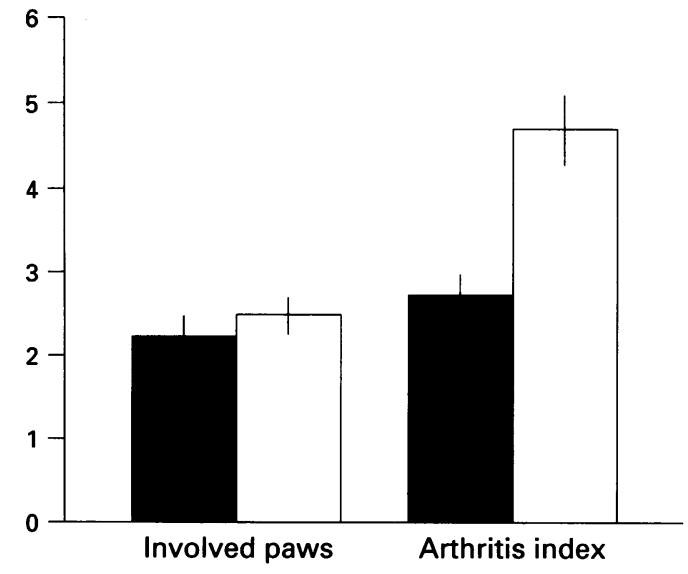

Figure 2 Effect of staphylococcal enterotoxin B (SEB) on the severity of type II collagen induced arthritis. Groups of $10 \mathrm{DBA} / 1$ mice were injected intraperitoneally with $40 \mu \mathrm{g}$ $S E B$ in sterile saline ( $\square$ ), or sterile saline alone (control) (D) at day-1. Arthritic mice were assessed for the severity of disease (disease index) and the number of involved limbs (means, SEM).

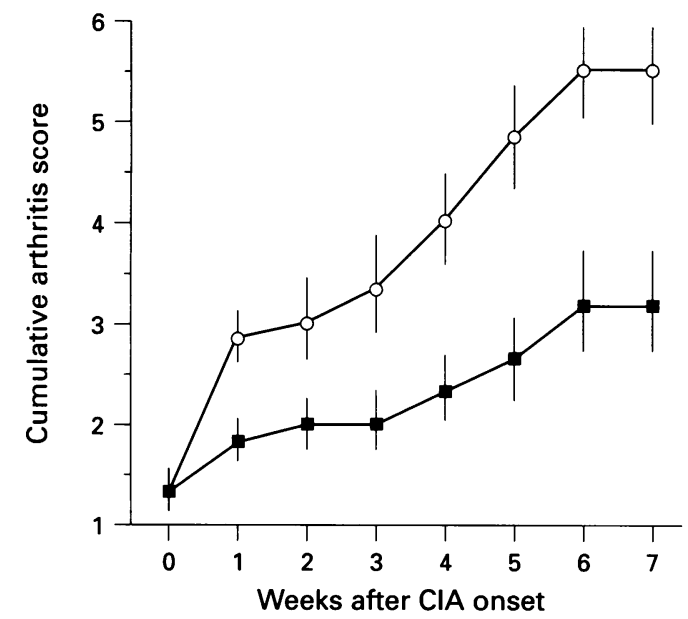

Figure 3 Effect of staphylococcal enterotoxin B (SEB) on the progression of type II collagen induced arthritis (CIA): mean (SEM) arthritis index. Arthritic $D B A / 1$ mice were injected intraperitoneally with $40 \mu \mathrm{g} S E B$ in sterile saline (O), or sterile saline alone (control) (D) at the first visible appearance of arthritis. Both groups, $n=12$.

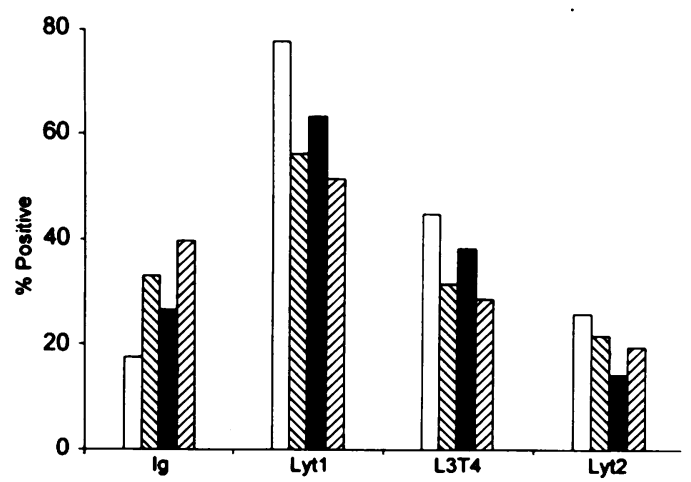

Figure 4 Flow cytometric analysis of lymphocyte markers on lymph node cells from mice sacrificed 21 days after collagen or control (saline) immunisation: mean percentage of cells staining positive for surface immunoglobulin (Ig), the pan T cell marker CDS (Lyt1), the CD4 T cell subset (L3T4), and the CD8 T cell subset (Lyt2). $\square=$ Normal controls; $\mathbb{N}=$ staphylococcal enterotoxin $B$ (SEB) alone; $\square=$ collagen induced arthritis + saline; $\square=$ collagen induced arthritis $+S E B$. The SEM of each group (not shown) did not exceed $5 \%$ of the mean for any determination. mice sacrificed 21 days after injection of CII. All mice immunised with CII showed a marked increase in Ig positive (B) cells compared with saline injected control DBA/1 mice. The Ig positive cell population of CII immunised, saline injected mice $(26.5 \%)$ was significantly increased $(p<0.025)$ compared with the normal controls $(16 \cdot 3 \%)$. However, the percentage of $\mathrm{Ig}$ positive cells in mice immunised with CII and injected with SEB $(39 \cdot 7 \%)$ was significantly increased compared with CII immunised, saline injected mice $(p<0.04) . D B A / 1$ mice injected with SEB, but not immunised with CII also demonstrated a significant increase in Ig positive cells $(33.0 \%)$ $(\mathrm{p}<0.05)$ compared with the normal control mice. There were corresponding significant decreases in the proportion of lymph node CD5 $\mathrm{T}$ cells from these populations, and the numbers of CD5 cells from CII immunised, SEB treated mice $(51.6 \%)$ were significantly reduced compared with $\mathrm{CII}$ immunised, saline injected mice $(64.5 \%)(p<0.05)$. However, data from $\mathrm{T}$ cell phenotyping for CD4 and CD8 did not suggest that either subset was specifically affected by the enterotoxin therapy (fig 4).

The antibody library used for the two colour flow cytometric analysis of $\mathrm{T}$ cell receptor expression in mice accounted for $81 \cdot 7-95 \cdot 0 \%$ of CD3 $\mathrm{T}$ cells (fig 5). Immunisation with CII alone did not cause any significant variations in the lymph node TCR V $\beta$ repertoire in comparison with the $V \beta$ distribution seen in normal DBA/ 1 mice, although the proportion of V $\beta 8$ cells $(23.6 \%)$ was increased compared with normal $(18 \cdot 7 \%)$. In contrast, injection with SEB alone caused a significant decrease $(\mathrm{p}<0.05)$ in $\mathrm{V} \beta 8$ cells. DBA/ 1 mice immunised with CII and injected with SEB also showed a significant decrease in V $\beta 8$ cells, when compared with either CII injected or control DBA $/ 1$ mice $(p<0.025$ for both determinations). CII immunised DBA/1 mice injected with SEB also showed significantly decreased levels of V $\beta 6$ cells when compared with CII injected, saline injected DBA/1 mice, or normal control mice $(p<0.05)$. The proportion of $\mathrm{V} \beta 6 \mathrm{~T}$ cells in $\mathrm{DBA} / 1$ mice injected with SEB alone was not significantly different from that of V $\beta 6 \mathrm{~T}$ cells in normal DBA/1 mice.

In contrast to the analysis 21 days after immunisation, flow cytometric analysis of $\mathrm{T}$ cell $\mathrm{V} \beta$ receptor expression in mice sacrificed 70 days after $\mathrm{CII}$ immunisation showed no significant variations in the $\mathrm{T}$ cell repertoire $(\mathrm{V} \beta 2,3,5,6,7,8,9,11,14)$ between the enterotoxin treated mice and controls (data not shown).

INFLUENCE OF ENTEROTOXIN PRETREATMENT ON THE IMMUNE RESPONSE

Anti-bovine type II collagen antibody levels, determined by ELISA, indicated that all mice developed a vigorous antibody response to collagen. The amount of anti-CII antibody in SEB treated mice was not significantly different from controls. No remarkable 


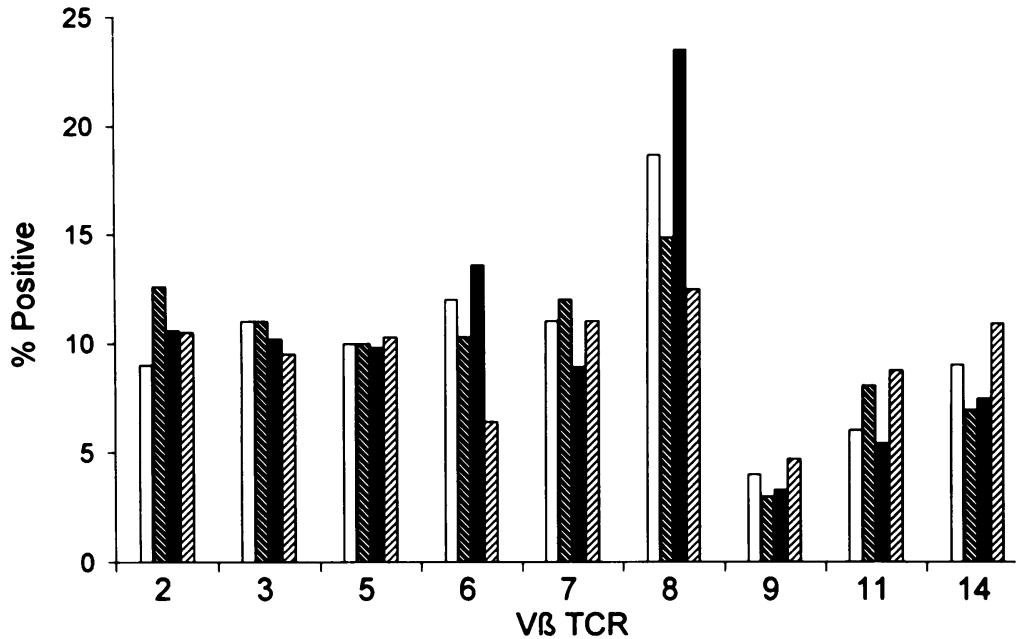

Figure 5 Flow cytometric analysis of T cell receptor (TCR) V $\beta$ markers on lymph node cells from mice sacrificed 21 days after collagen or control (saline) immunisation: mean percentage of cells staining positive for each $V \beta$ antiserum. $\square=$ Normal controls; $\mathbb{Q}=$ staphylococcal enterotoxin $B$ (SEB) alone; = collagen induced arthritis + saline; $\square=$ collagen induced arthritis + SEB. The SEM of each group (not shown) did not exceed $5 \%$ of the mean for any determination. variations in the proliferative responses to mitogens, enterotoxin, or collagen in vitro were seen between SEB treated mice and controls, when mice were assessed 70 days after immunisation (data not shown).

\section{Discussion}

Collagen induced arthritis in mice appears to represent a sound model of rheumatoid arthritis, resembling a number of the immunological and histopathological features of RA. CIA is an MHC restricted disease, occurring only in $\mathrm{H}-2^{\mathrm{q}}$ and $\mathrm{H}-2^{\mathrm{r}}$ phenotype mice. ${ }^{2}{ }^{23}$ This restriction may occur at the level of antigen presentation, as sequences in both the $\mathrm{I}-\mathrm{A}^{\mathrm{q}} \alpha$ and I-A $\mathrm{A} \beta$ chains $^{3{ }^{24}}$ have been implicated in collagen peptide presentation. However, the specificity of collagen responsive $T$ cells may also regulate the development of disease. The CIA resistant SWR $\left(\mathrm{H}_{-} 2^{\mathrm{q}}\right)$ strain has a major deletion in the TCR V $\beta$ genes, which could account for the failure of SWR to develop collagen reactive $T$ cells that participate in the pathogenesis of arthritis. In particular, the V $\beta 8$ $T$ cell subset has been implicated in the arthritogenic response to collagen, by studies examining the restricted heterogeneity of TCR $\mathrm{V} \beta$ usage in lymph nodes and joints from CIA mice $^{25}$ and using monoclonal antibody immunotherapy to deplete $V \beta 8 \mathrm{~T}$ cells from collagen immunised mice. ${ }^{9}{ }^{26}$ The V $\beta 8 \mathrm{~T}$ cell has also been implicated in the development of murine experimental autoimmune encephalomyelitis $^{27}$ and murine lupus. ${ }^{28}$ However, the role of the V $\beta 8 \mathrm{~T}$ cell subset in the development of CIA remains controversial ${ }^{29}{ }^{30}$ as SWR mice are complement (C5) deficient and may be resistant to arthritis because of the role of complement in the inflammatory process. ${ }^{8} 3132$ Nevertheless, the participation of a limited $T$ cell response in the pathogenesis of arthritis remains an attractive hypothesis, particularly considering the recent demonstration of the accumulation of TCR V $\beta 14$ cells within the rheumatoid joint. ${ }^{33}$ Therefore, modulation of the $\mathrm{T}$ cell repertoire using superantigen immunotherapy appeared to represent a viable approach to the treatment of autoimmune disease in which limited TCR usage is responsible for the development of autoimmunity.

SEB immunotheraphy has already shown the potential for modulation of murine models of autoimmune disease, with positive effects reported in MRL $1 \mathrm{pr} / \mathrm{lpr}$ disease. ${ }^{34}$ In that study, V $\beta 8 \mathrm{~T}$ cells were reduced in both spleen and lymph nodes from MRL lpr/lpr mice, and the SEB therapy resulted in the improvement of both the clinical and immunological features of murine lupus. However, intra-articular injection of SEB in V $\beta 8.2$ transgenic MRL lpr/ lpr mice gave rise to a chronic arthritis, ${ }^{35}$ suggesting that the chronic joint disease in this model was adversely affected. Our data suggest that staphylococcal enterotoxins were not immunosuppressive in collagen immunised mice at any administration time point examined. $\mathrm{DBA} / 1$ mice injected with a single dose of SEB at the time of CII immunisation developed arthritis faster, and exhibited more severe disease signs, than control animals. Administration of SEB subsequent to the appearance of CIA also resulted in a more severe arthritis. The precise cause of the increased disease severity is not clear, as the immune response to collagen was not increased in SEB treated mice. The flow cytometric data indicated changes in both $B$ cells and $T$ cells in enterotoxin treated, CII immunised mice. As predicted by published studies on the in vivo and in vitro effects of enterotoxins, ${ }^{10} 1334$ treatment with SEB before immunisation with CII caused changes in the TCR repertoire of $\mathrm{DBA} / 1$ mice. These changes in $\mathrm{T}$ cell $\mathrm{V} \beta$ expression were detected 21 days after injection of enterotoxin but were not apparent 70 days after injection. A decrease in TCR V $\beta 8$ expression occurred in lymph node cells from both collagen immunised and normal mice in response to SEB injection. The decrease in V $\beta 8$ cells is consistent with the elimination of the V $\beta 8$ subset reported in both adult and neonatal mice, ${ }^{10}{ }^{34}$ although Marrack et al demonstrated an increase in V $\beta 8$ cells in adult B10.BR mice injected with SEB. ${ }^{13}$ In our study, the V $\beta 3$ subset in adult DBA/ 1 mice was not affected by the immunotherapy, whereas a $1-2 \%$ decrease in V $\mathrm{V} 3 \mathrm{~T}$ cells was seen by Marrack's group. We did not observe changes the V $\beta 7$ subpopulation, which occur only with high (100 $\mu \mathrm{g})$ dose treatment. V $\beta 6 \mathrm{~T}$ cells were not affected by the injected of SEB in normal DBA/1 mice. However, SEB caused a decrease in the V $\beta 6$ subset in mice immunised with CII. This result was not predicted by the known $\mathrm{T}$ cell specificity of the enterotoxins. Previous reports have suggested that the modification of the $\mathrm{T}$ cell repertoire by SEB acts as an immunosuppressive agent, ${ }^{17} 36$ possibly by the induction of $\mathrm{T}$ cell anergy in cells bearing a TCR engaged by the superantigen. ${ }^{37}$ However, the phenotypic changes induced by SEB during the response to collagen did not result in immunosuppression and reduced disease. There was no obvious preference in the SEB effects for either $\mathrm{CD} 4$ or $\mathrm{CD} 8 \mathrm{~T}$ cells in 
collagen injected mice. Our data suggest that SEB does not suppress the immunological or arthritogenic response to CII, but actually enhances the disease. Furthermore, this proarthritic effect occurred irrespective of the time of administration of SEB. It is possible either that collagen reactive $V \beta 8$ or V $\beta 6 T$ cells, or both, are preserved during SEB immunotherapy, or that the V $\beta 8$ or V $\beta 6 \mathrm{~T}$ cell population is not essential for the development of CIA, as suggested by Holmdahl et al. ${ }^{4}$ However, it is possible also that the effect is independent of specific influences on the $T$ cell repertoire in the $\mathrm{DBA} / 1$ mice, as the introduction of enterotoxins in collagen immunised mice may promote increased cytokine activity in synovial cells, ${ }^{38}$ and it has been demonstrated that increased levels of interleukins and interferon promote CIA. ${ }^{39-42}$ Although our data suggest that the anti-collagen antibody levels were not influenced by SEB immunotheraphy, it is possible that the endotoxin may influence the amount of antibody directed against murine type II collagen, which is more closely related to the development of CIA. ${ }^{43}$ Further studies are necessary to determine the mechanism by which SEB influences this experimental model of arthritis.

Our results suggest that the concept of $T$ cell modification using superantigen immunotherapy may be problematic, because the $T$ cell subsets modified in vivo did not correlate completely with the predictions based on in vitro studies, and the nature of the specific autoimmune response may be critical to the outcome of the immunotherapy. The precise immunogenetic aspects of the autoimmune disease may also play a crucial role in the outcome, as a similar approach to the treatment of CIA induced by B10.RIII mice using SEB has demonstrated disease suppression. $^{44}$ However, this $\mathrm{H}-2^{\mathrm{r}}$ strain responds to a different epitope on the CII molecule, ${ }^{23}$ and TCR usage in B10.RIII mice immunised with porcine collagen may vary markedly from that in $\mathrm{DBA} / 1$ mice injected with bovine collagen. Marked differences between $\mathrm{H}-2^{\mathrm{q}}$ and $\mathrm{H}-2^{\mathrm{r}}$ haplotype mice were observed in the response to immunotherapy using monoclonal antibodies directed against the class II MHC molecule, with B10.RIII mice developing a more severe arthritis after the injection of an anti-I-E antibody. ${ }^{45}$

At present, the specificity of the $T$ cell autoimmune response in rheumatoid arthritis is unknown, and the response may be directed against several self components. Current reports suggest that the $T$ cell receptor expression in synovial fluid and synovial tissue is polyclonal and varies within the RA population. ${ }^{46-48}$ It will therefore be important to determine the precise nature of the $T$ cell response in RA patients before a superantigen therapy should be considered in human autoimmune disease.

This work was supported by grants from the Arthritis Foundation (Michigan Chapter), Hutzel Hospital, and the Alumni of Wayne State University. Dr Cingel was the recipient of an Arthritis Foundation Medical Student Travel award for the presentation of this work in Abstract form. The authors thank Julie Dutcher for expert technical assistance on this study.
1 Panayi G S, Wooley P H, Batchelor J R. Genetic basis of rheumatoid disease: HLA antigens, disease manifestations, and toxic reactions to drugs. $B M \mathcal{F} 1978 ; 2$ : 1326-8.

2 Wooley P H, Luthra H S, Stuart J M, David C S. Type II collagen-induced arthritis in mice. I. Major histocompatibility complex (I region) linkage and antibody correlates. $\mathcal{E}$ Exp Med 1981; 154: 688-700.

3 David C S. Genes for MHC, TCR and Mls determine susceptibility to collagen induced arthritis. Acta Pathol Microbiol Immunol Scand 1990; 98: 575-84.

4 Goldschmidt $T$ J, Jansson L, Holmdahl $R$. In vivo elimination of $\mathbf{T}$ cells expressing specific $T$-cell receptor $\mathrm{V}$ beta chains in mice susceptible to collagen-induced arthritis. Immunology 1990; 69: 508-14

5 Blackman M A, Gerhard-Burgert $\mathrm{H}$, Woodland D L, Palmer E, Kappler J W, Marrack P. A role for clonal inactivation in $\mathrm{T}$ cell tolerance to Mls-1a. Nature 1990;345:540-2.

6 Herman A, Kappler J W, Marrack P, Pullen A M. Superantigens: Mechanism of T-cell stimulation and role in immune responses. Ann Rev Immunol 1991; 9: in imm $745-72$.

7 Behlke M A, Chou H S, Huppi K, Loh D Y. Murine T cell receptor mutants with deletions of b-chain variable region receptor mutants with deletions of b-chain variable

8 Watson W C, Townes A S. Genetic susceptibility to murine collagen II autoimmune arthritis. Proposed relationship to the IgG2 autoantibody subclass response, complement C5, major histocompatibility complex (MHC) and nonMHC loci. $\mathcal{F} \operatorname{Exp}$ Med 1985; 162: 1878-91.

9 Osman G E, Toda M, Kanagawa O, Hood L E. Characterization of the $T$ cell receptor repertoire causing collagen arthritis in mice. $\mathcal{f}$ Exp Med 1993; 177: 387-95.

10 White J, Herman A, Pullen A M, Kubo R, Kappler J W, Marrack P. The V beta-specific superantigen staphylococcal enterotoxin B: stimulation of mature T cells and cloncal deletion in neonatal mice. Cell 1989; 56: 27-35.

11 Marrack P, Kappler J. The staphylococcal enterotoxins and their relatives. Science 1990; 248: 705-11.

12 Takimoto $\mathrm{H}$, Yoshikai Y, Kishihara $\mathrm{K}$, et al. Stimulation of all $\mathrm{T}$ cells bearing $\mathrm{V}$ beta $1, \mathrm{~V}$ beta $3, \mathrm{~V}$ beta 11 and $\mathrm{V}$ beta 12 by staphylococcal enterotoxin A. Eur $\mathcal{F}$ Immunol 1990; 20: 617-21.

13 Marrack P, Blackman M, Kushnir E, Kappler J. The toxicity of staphylococcal enterotoxin $B$ in mice is mediated by $T$ cells. $\mathcal{F}$ Exp Med 1990; 171: 455-64.

4 Rellahan B L, Jones L A, Kruisbeek A M, Fry A M, Matis $\mathrm{L} A$. In vivo induction of anergy in peripheral $\mathrm{V}$ beta $8+$ $\mathrm{T}$ cells by staphylococcal enterotoxin B. $\mathcal{F}$ Exp Med 1990; 172: 1091-100.

15 Kawabe Y, Ochi A. Selective anergy of V beta $8+, C D 4+T$ cells in Staphylococcus enterotoxin B-primed mice. $\mathcal{f}$ Exp Med 1990; 172: 1065-70.

16 Smith B G, Johnson H J. The effect of staphylococcal enterotoxins on the primary in vitro immune response. $\mathcal{F}$ Immunol 1975; 115; 575-81.

17 Lin Y S, Hu S C, Jan M S, Rogers T J. Inhibition of the delayed-type hypersensitivity response by staphylococcal enterotoxin B-induced suppressor T cells. Cell Immunol 1991; 132: 532-8.

18 Wooley $\mathrm{P}$ H. Collagen-induced arthritis in the mouse. Methods Enzymol 1988; 162: 361-73.

19 Wooley P H, Whalen J D. Pristane-induced arthritis in mice. III. Lymphocyte phenotypic and functional abnormalities precede the development of pristane-induced arthritis. Cell Immunol 1991; 138: 251-9.

20 Wooley P H, Whalen J D, Warner L M, Losten M K, Chapdelaine J M. Type II collagen induced arthritis in mice. V. The role of the spleen cell response in the immune and arthritogenic reaction to type II collagen. $f$ Rheumatol 1989; 16: 1192-6.

21 Wooley P H, Seibold J R, Whalen J D, Chapdelaine J M. Pristane-induced arthritis. The immunological and genetic features of an experimental murine model of autoimmune disease. Arthritis Rheum 1989; 32: 1022-30.

22 Levitt N G, Fernandez-Madrid F, Wooley P H. Pristane induced arthritis in mice. IV. Immunotherapy with monoclonal antibodies directed against lymphocyte subsets. F Rheumatol 1992; 19: 1342-7.

23 Wooley P H, Luthra H S, Griffiths M M, Stuart J M, Huse A, David C S. Type II collagen-induced arthritis in mice. IV. Variations in immunogenetic regulation provide evidence for multiple arthritogenic epitopes on the evidence for multiple arthritogenic epitopes on
collagen molecule. F Immunol 1985; 135: 2443-51.

24 Holmdahl $R$, Karlsson M, Andersson M E, Rask L, Andersson L. Localization of a critical restriction site on the I-A beta chain that determines susceptibility to collagen-induced arthritis in mice. Proc Natl Acad Sci USA 1989; 86: 9475-9.

25 Haqqi T M, Anderson G D, Banerjee S, David C S. Restricted heterogeneity in $\mathrm{T}$-cell antigen receptor $\mathrm{V}$ beta gene usage in the lymph nodes and arthritic joints of mice. Proc Natl Acad Sci USA 1992; 89: 1253-5.

26 Moder K G, Luthra H S, Griffiths M, David C S. Prevention of collagen induced arthritis in mice by deletion of $\mathrm{T}$ cell receptor $\mathrm{V}$ beta 8 bearing $\mathrm{T}$ cells with monoclonal antibodies. Br 7 Rheumatol 1993; 32: 26-30.

27 Zamvil S S, Mitchell D J, Lee N E, et al. Predominant expression of a $T$ cell receptor $V \beta$ gene subfamily in autoimmune encephalomyelitis. $f$ Exp Med 1988; 167: 1586-96.

28 Mountz J D, Huppi K E, Seldin M F, Mushinski J F, Steinberg A $D$. T cell receptor gene expression in autoimmune mice. f Immunol 1986; 137: 1029-34. 
29 David C S. Role for T-cell receptor V $\beta$ genes in collagen induced-arthritis [letter]. Immunogenetics 1992; 35: induced-ar $69-70$.

30 Andersson $M$, Jansson L, Holmdahl R. Role for T-cell receptor $\mathrm{V} \beta$ genes in collagen induced-arthritis. Immunogenetics 1992; 35: 71-2

31 Spinella D G, Jeffers J R, Reife R A, Stuart J M. The role of $\mathrm{C} 5$ and $\mathrm{T}$-cell receptor $\mathrm{V} \beta$ genes in susceptibility to collagen-induced arthritis. Immunogenetics 1991; 34 23-7.

32 Noguchi K, Inagawa H, Tsuji Y, Morikawa A, Mizuno D, Soma G. Antitumor activity of a novel chimera tumor necrosis factor (TNF-STH) constructed by connecting rTNF-S with thymosin beta 4 against murine syngeneic tumors FImmunother 1991; 10: 105-11.

33 Paliard X, West S G, Lafferty J A, et al. Evidence for the effects of a superantigen in rheumatoid arthritis. Science effects of a superant

$34 \mathrm{Kim}$ C, Siminovitch K A, Ochi A. Reduction of lupus nephritis in MRL/pr mice by a bacterial superantigen treatment. $\mathcal{F}$ Exp Med 1991; 174: 1431-7.

35 Mountz J D, Zhou T, Long R E, et al. Factors influencing development of $\mathrm{T}$ cell dependent vs. non- $\mathrm{T}$ cell dependent arthritis. Arthritis Rheum 1992; 35: S98.

36 Patel M, Taub D D, Lin Y S, Rogers T J. Immunosuppressive activity of staphylococcal enterotoxin B. I. Characterization of staphylococcal enterotoxin-B-induced suppressor cells. Cell Immunol 1990; 131: 159-69.

37 Kawabe Y, Ochi A. Selective anergy of $\mathrm{V} \beta 8^{+}, \mathrm{CD} 4^{+} \mathrm{T}$ cells in staphylococcus enterotoxin B-primed mice. $\mathcal{F}$ Exp Med in staphylococcus enter

38 Mourad W, Mehindate K, Schall T J, McColl S R. Engagement of major histocompatibility complex class II molecules by superantigen induces inflammatory cytokine gene expression in human rheumatoid fibroblast-lik synoviocytes. F Exp Med 1992; 175: 613-6.

39 Nakajima H, Takamori H, Hiyama Y, Tsukada W. The effects of treatment with interferon-gamma on type II collagen-induced arthritis. Clin Exp Immunol 1990; 81: 441-5.
40 Takai Y, Seki N, Senoh H, et al. Enhanced production of interleukin-6 in mice with type II collagen-induced arthritis. Arthritis Rheum 1989; 32: 594-600

41 Cooper W O, Fava R A, Gates C A, Cremer M A, Townes A S. Acceleration of onset of collagen-induced arthritis by intra-articular injection of tumour necrosis factor or transforming growth factor-beta. Clin Exp Immunol 1992; 89: 244-50.

42 Hom J T, Cole H, Estridge T, Gliszczynski V L. Interleukin1 enhances the development of type II collagen-induced arthritis only in susceptible and not in resistant mice. Clin Immunol Immunopathol 1992; 62: 56-65.

43 Holmdahl R, Jansson L, Gullberg D, Rubin K, Forsberg P $\mathrm{O}$, Klareskog L. Incidence of arthritis and autoreactivity of anti-collagen antibodies after immunization of DBA $/ 1$ mice with heterologous and autologous collagen II. Clin Exp Immunol 1985; 62: 639-46.

44 Moder K G, Nabozny G, Bull M, Luthra H S, David C S. Modulation of the $\mathrm{T}$ cell receptor $\mathrm{V} \beta$ repertoire with superantigens reduces susceptibility to collagen-induced arthritis [abstract]. Arthritis Rheum 1992; 35: S193.

45 Wooley P H, Luthra H S, Lafuse W P, Huse A, Stuart J M David C S. Type II collagen-induced arthritis in mice. III Suppression of arthritis by using monoclonal and polyclonal anti-Ia antisera. $\mathcal{F}$ Immunol 1985; 134: 2366-74.

46 Bucht A, Oksenberg J R, Lindblad S, Gronberg A, Steinman L, Klareskog L. Characterization of T-cell receptor alpha beta repertoire in synovial tissue from different temporal phases of rheumatoid arthritis. Scand 7 Immunol 1992; 35: 159-65.

47 Olive C, Gatenby P A, Serieantson S W. Analysis of T cell receptor $\mathrm{V}$ alpha and $\mathrm{V}$ beta gene usage in synovia of patients with rheumatoid arthritis. Immunol Cell Biol 1991; 69: 349-54

48 Hakoda $M$, Ishimoto $T$, Yamamoto $\mathrm{K}$, et al. Clonal analysi of $\mathrm{T}$ cell infiltrates in synovial tissue of patients with rheumatoid arthritis. Clin Immunol Immunopathol 1990 57: 387-98. 